\title{
Influence of processing on microstructure and electrical characteristics of multilayer varistors
}

\author{
D. SZWAGIERCZAK ${ }^{*}$, J. KULAWIK, A. SKWAREK \\ Institute of Electron Technology, Kraków Division, Zabłocie 39, 30-701 Kraków, Poland \\ Received: September 11, 2018; Revised: February 18, 2019; Accepted: March 9, 2019 \\ (c) The Author(s) 2019.
}

\begin{abstract}
The paper reports on the influence of processing on microstructure and electrical properties of multilayer varistors based on zinc oxide doped with $\mathrm{Bi}_{2} \mathrm{O}_{3}, \mathrm{Sb}_{2} \mathrm{O}_{3}, \mathrm{Co}_{2} \mathrm{O}_{3}, \mathrm{MnO}, \mathrm{Cr}_{2} \mathrm{O}_{3}, \mathrm{~B}_{2} \mathrm{O}_{3}$, and $\mathrm{SiO}_{2}$. $0.5-1 \mathrm{wt} \%$ of $\mathrm{AlF}_{3}-\mathrm{CaB}_{4} \mathrm{O}_{7}$ was used as a new effective sintering aid. The behavior of green laminates during heating was characterized using differential thermal analysis and a heating microscope. As revealed by XRD, SEM, and EDS methods, the varistor layers are composed of ZnO grains of $1-5 \mu \mathrm{m}$ size, submicrometer spinel and pyrochlore grains situated at the $\mathrm{ZnO}$ grain boundaries, and nanometric $\mathrm{Bi}_{2} \mathrm{O}_{3}$-rich films surrounding $\mathrm{ZnO}$ grains. Complex impedance studies carried out in the frequency range of $0.01 \mathrm{~Hz}-2 \mathrm{MHz}$ at temperatures changing from -30 to $150{ }^{\circ} \mathrm{C}$ imply the formation of semiconducting grains and insulating grain boundaries. Frequency dependence of dielectric permittivity shows a high plateau at lower frequencies, typical for barrier layer capacitance effect. The fabricated multilayer varistors show nonlinear current-voltage characteristics with a high nonlinear coefficient of 26-38. The breakdown voltage was found to decrease within the range of $66-130 \mathrm{~V}$ with sintering temperature increasing from 1000 to $1100{ }^{\circ} \mathrm{C}$. Good surge current capability of the varistors was confirmed by the tests using $8 / 20 \mu$ s pulses.
\end{abstract}

Keywords: multilayer varistor; tape casting; microstructure; current-voltage characteristic

\section{Introduction}

Varistors which show nonlinear current-voltage characteristics are widely applied for protection of electronic devices against transient overvoltages and current surges caused by lightning, switching of high power devices, and electrostatic discharge (ESD). Varistor behavior is attributed to the formation of double Schottky barriers at grain boundaries of semiconducting grains. Since decades zinc oxide has been a leading material for varistor ceramics [1-18]. For preparation of varistor

* Corresponding author.

E-mail: dszwagi@ite.waw.pl ceramic powders, different methods were used, like solid state reaction, sol-gel, combustion synthesis plasma pyrolysis, micro-emulsion synthesis, precipitation [3]. For sintering of varistors, different techniques were applied including conventional sintering, step sintering, spark plasma, and microwave methods.

Appropriate doping of $\mathrm{ZnO}$ is necessary to attain the desired varistor properties [5-17]. Typical oxide dopants include $\mathrm{Bi}_{2} \mathrm{O}_{3}, \mathrm{~B}_{2} \mathrm{O}_{3}, \mathrm{SiO}_{2}, \mathrm{Al}_{2} \mathrm{O}_{3}, \mathrm{Sb}_{2} \mathrm{O}_{3}, \mathrm{Co}_{2} \mathrm{O}_{3}, \mathrm{MnO}_{2}$, $\mathrm{Cr}_{2} \mathrm{O}_{3}, \mathrm{TiO}_{2}, \mathrm{La}_{2} \mathrm{O}_{3}, \operatorname{PrO}_{x}, \mathrm{~V}_{2} \mathrm{O}_{3}$. Recently, further additives that can improve varistor electrical properties such as $\mathrm{Ga}_{2} \mathrm{O}_{3}$ [5], $\mathrm{Na}_{2} \mathrm{CO}_{3}$ [6] have been reported. Among new varistor compositions, those based on $\mathrm{ZnO}-\mathrm{V}_{2} \mathrm{O}_{5}$ have recently attracted much attention due 
to their low sintering temperature around $900{ }^{\circ} \mathrm{C} \quad[7,8]$.

Tailoring of the properties of the potential barrier is a complex interplay of the composition and level of dopants, as well as oxygen content related to thermal treatment conditions. Each of the dopant oxides has its essential contribution to the creation of the demanded microstructure and varistor nonlinear characteristics. The key role is attributed to those additives which form double Schottky barriers at grain boundaries: $\mathrm{Bi}_{2} \mathrm{O}_{3}$, $\mathrm{PrO}_{x}, \mathrm{Co}_{2} \mathrm{O}_{3}, \mathrm{SnO}_{2}, \mathrm{NiO}$. In the most popular $\mathrm{ZnO}-\mathrm{Bi}_{2} \mathrm{O}_{3}$ varistors, intergranular layers responsible for creation of double Schottky barriers are formed during sintering by the $\mathrm{Bi}_{2} \mathrm{O}_{3}$-rich liquid phase containing dissolved other dopants. Very important dopants responsible for ensuring good nonlinear properties are transition metal oxides, such as $\mathrm{Co}_{2} \mathrm{O}_{3}, \mathrm{MnO}_{2}, \mathrm{Cr}_{2} \mathrm{O}_{3}, \mathrm{TiO}_{2}$. Some dopants as $\mathrm{MnO}_{2}, \mathrm{SiO}_{2}$ serve as sintering aids, and others, like $\mathrm{Sb}_{2} \mathrm{O}_{3}, \mathrm{Al}_{2} \mathrm{O}_{3}, \mathrm{MgO}, \mathrm{TiO}_{2}, \mathrm{Cr}_{2} \mathrm{O}_{3}, \mathrm{Fe}_{2} \mathrm{O}_{3}$, inhibit excessive grain growth. Some additives have simultaneously a few functions, e.g., $\mathrm{SiO}_{2}$ can both lower sintering temperature and decrease grain size of $\mathrm{ZnO}$, as well as increase the potential barrier height which leads to the improved nonlinear characteristics [9].

In general, larger ions of $\mathrm{Bi}, \mathrm{Ba}, \mathrm{Sr}, \mathrm{Pr}$ show tendency to segregate at grain boundary region. Smaller ions of $\mathrm{Mn}, \mathrm{Co}, \mathrm{Ni}, \mathrm{Cr}, \mathrm{Al}$ can create trap states both in $\mathrm{ZnO}$ grain interiors and at grain boundaries. Dopants entering $\mathrm{ZnO}$ grains can form shallow donor levels with the activation energies of about $0.05 \mathrm{eV}$ or deep donor levels with the activation energies higher than $1.65 \mathrm{eV}$ [10]. Bulk traps in $\mathrm{ZnO}$ are also attributed to intrinsic defects, such as doubly ionized zinc interstitial $\mathrm{Zn}_{\mathrm{i}}{ }^{*}$ with the activation energy of $0.20-0.26 \mathrm{eV}$ and singly ionized oxygen vacancies $\mathrm{V}_{\mathrm{O}}{ }^{\cdot}$ with the activation energy of about $0.35 \mathrm{eV}$ [17]. Typically, the doping level of $\mathrm{ZnO}$ ceramics is $0.2-1 \mathrm{~mol} \%$.

A very important factor influencing the barrier height and consequently proper varistor properties is oxygen content in the grain boundary region [19]. In the degraded $\mathrm{ZnO}$ varistors, a significant oxygen deficit was observed. Furthermore, thermal treatment in O-rich atmosphere was found to result in recovery of the degraded varistors [20]. During sintering diffusion of oxygen proceeds easily in $\mathrm{Bi}_{2} \mathrm{O}_{3}$ rich phase surrounding $\mathrm{ZnO}$ grains since $\mathrm{Bi}_{2} \mathrm{O}_{3}$ is a good ionic conductor with a high oxygen vacancy concentration.

Growing application range of low voltage devices and strong demand for miniaturization and enhanced integration scale in electronics stimulate development of multilayer varistors [21-41]. These elements destined for surge protection of integrated circuits, hybrid circuits, and surface mount circuits, are fabricated by co-sintering of several tape cast ceramic foils with screen printed internal electrodes connected in parallel. The dense, fine-grained, and uniform microstructure is crucial for good properties of multilayer varistors. Uniform dopant distribution inside the entire varistor is known to improve significantly leakage current and nonlinear properties of a varistor [22]. Furthermore, broad grain size distribution has been reported to cause poor performance in ESD conditions and shorter life time of multilayer varistors [23]. Pr doped $\mathrm{ZnO}$ multilayer chip varistors were found to exhibit better ESD withstand capability than those based on $\mathrm{Bi}$ doped $\mathrm{ZnO}$ [24].

The paper describes processing, microstructure, composition, electrical characteristics, and surge current capability of multilayer varistors based on doped zinc oxide. In the present investigation, the materials with the composition and level of dopants optimized basing on our previous studies [33,34] were utilized for preparation of green varistor tapes. The literature devoted to LTCC processing of multilayer varistors and characterization of green varistor tapes is scarce. This paper was focused on LTCC process of multilayer varistor fabrication comprising tape casting, lamination, and cosintering as well as on optimization of thermal treatment conditions by means of differential thermal analysis and heating microscope studies. Furthermore, the influence of sintering temperature and the effect of a sintering aid $\mathrm{AlF}_{3}-\mathrm{CaB}_{4} \mathrm{O}_{7}$ on microstructure and nonlinear behavior of the fabricated varistors were investigated.

\section{Experimental}

Multilayer varistors were fabricated in a process which included several operations: preparation of slurry, tape casting of doped $\mathrm{ZnO}$ ceramic foils, laser cutting of green sheets, screen printing of internal electrodes, stacking of green sheets, isostatic lamination, dicing into individual varistors, firing of multilayer varistors, deposition, and firing of $\mathrm{Ag}$ external connections of internal electrodes.

For preparation of a slurry, the powder obtained by the coprecipitation method based on $\mathrm{ZnO}$ doped with $\mathrm{Bi}_{2} \mathrm{O}_{3}, \mathrm{Sb}_{2} \mathrm{O}_{3}, \mathrm{CoO}, \mathrm{MnO}, \mathrm{Cr}_{2} \mathrm{O}_{3}, \mathrm{~B}_{2} \mathrm{O}_{3}$, and $\mathrm{SiO}_{2}$ was ball-milled with organic additives. The composition of 
the inorganic part of the slurry is shown in Table 1. This composition was optimized basing on the results of our previous studies [33,34], where the use of different levels of $\operatorname{Pr}_{2} \mathrm{O}_{3}, \mathrm{CoO}$, and $\mathrm{Sb}_{2} \mathrm{O}_{3}$ dopants has led to worse electrical characteristics. The organic components applied in the slurry comprised polyvinyl butyral as a binder, fish oil as a dispersant, polyethylene glycol and dibutyl phthalate as plasticizers, toluene and isopropyl alcohol as solvents. The composition of the slurry is given in Table 2 .

In an additional version of the basic varistor composition, in order to decrease the sintering temperature, $0.5-1 \mathrm{wt} \%$ of a low melting mixture $\mathrm{AlF}_{3}-\mathrm{CaB}_{4} \mathrm{O}_{7}$ (1:1 molar ratio) was used as a sintering aid.

Tape casting (TTC-1200, Mistler, USA) was applied for obtainment of ceramic flexible tapes. After casting, the green tapes were dried at room temperature and at $50{ }^{\circ} \mathrm{C}$ for a few hours. Then, sheets with desired dimensions and holes for positioning were cut by a laser (E-355-3-G-OA, Oxford Lasers, UK). For basic composition, internal electrodes made of a commercial thick film Pt paste were deposited using screen printing technique. For the composition with $\mathrm{AlF}_{3}-\mathrm{CaB}_{4} \mathrm{O}_{7}$, an Ag commercial paste was utilized. After stacking of 5-10 green ceramic sheets with electrodes separated by 1-3 layers of blank sheets, isostatic lamination was performed under a pressure of $30 \mathrm{MPa}$ at $70{ }^{\circ} \mathrm{C}$ (IL-4008PC, Pacific Trinetics Corporation, USA).

The observation of green laminates in a Leitz heating microscope provided information about optimal sintering range of ceramics and proper quality of lamination process. Images which illustrate changes of the shape and

Table 1 Composition of the inorganic part of the varistor slurry

$\begin{array}{lllllllllllllllll}\text { Oxide } & \mathrm{ZnO} & \mathrm{Bi}_{2} \mathrm{O}_{3} & \mathrm{Sb}_{2} \mathrm{O}_{3} & \mathrm{CoO} & \mathrm{MnO} & \mathrm{Cr}_{2} \mathrm{O}_{3} & \mathrm{~B}_{2} \mathrm{O}_{3} & \mathrm{SiO}_{2}\end{array}$

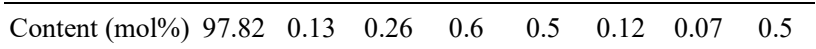

Table 2 Slurry composition for varistor tape casting

\begin{tabular}{cc}
\hline Slurry component & Content $(\mathrm{wt} \%)$ \\
\hline Ceramic powder & 54.0 \\
Polyvinyl butyral & 7.0 \\
Fish oil & 0.9 \\
Polyethylene glycol & 2.2 \\
Dibutyl phthalate & 2.2 \\
Isopropyl alcohol & 16.8 \\
Toluene & 16.9 \\
\hline
\end{tabular}

dimensions of green laminate samples were registered during heating up in the temperature range of $20-1350{ }^{\circ} \mathrm{C}$. Differential thermal analysis and thermogravimetric studies of green varistor tapes were performed using a Netzsch simultaneous thermal analyzer in order to determine the burnout range of organic components of the tape.

Green laminates were diced into individual varistors and subsequently fired according to the carefully adjusted profile with a maximum temperature of 1000-1100 and 920-950 ${ }^{\circ} \mathrm{C}$ held for $2 \mathrm{~h}$ for the basic varistor composition and the composition with $\mathrm{AlF}_{3}-\mathrm{CaB}_{4} \mathrm{O}_{7}$ addition, respectively. A final operation was deposition of external connections made of $\mathrm{Ag}$ paste and their firing at $850{ }^{\circ} \mathrm{C}$. Test varistor samples used for electrical characterization were $1 \mathrm{~mm}$ thick with the electrode surface area of $0.8 \mathrm{~cm}^{2}$.

The microstructure studies and elemental microanalysis of multilayer varistors were carried out using an FEI scanning electron microscope and the EDAX Genesis EDS system. The phase composition of the varistor ceramic layers was detected by a Philips X'Pert diffractometer.

Impedance spectroscopy method was used to investigate dielectric response of the varistors in the temperature range from -30 to $150{ }^{\circ} \mathrm{C}$ at frequencies ranging from $0.01 \mathrm{~Hz}$ to $2 \mathrm{MHz}$ (Atlas Sollich, Poland and Quadtech, USA).

A Keithley SourceMeter was applied for currentvoltage measurements of the fabricated multilayer varistors in a voltage range of $0-110 \mathrm{~V}$. Surge current capability of multilayer varistors was tested using a standard impulse current with waveform $8 / 20 \mu$ s for short-circuited output. The surge tests were performed using UCS 500-M Ultra Compact Simulator manufactured by EM Test. Voltage waveform was monitored using high voltage probe and current shape was observed as voltage drop on shunt resistor, both recorded on a Keysight MSO-X 3014T Oscilloscope. Initial and after surge characterization of the tested devices were performed using Source Measure Unit.

\section{Results and discussion}

The obtained varistor tapes were smooth and flexible with a good mechanical strength and uniform thickness. The thickness of the tape after drying was about $80 \mu \mathrm{m}$. In Fig. 1, the results of thermogravimetric studies and 


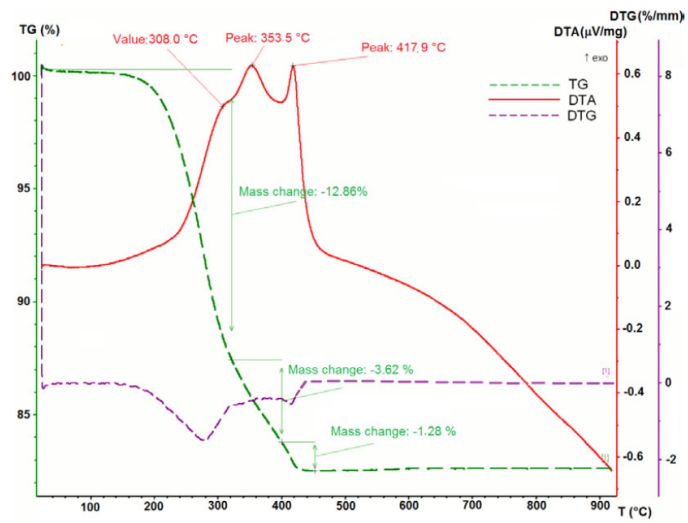

Fig. 1 Results of differential thermal analysis (DTA) and thermogravimetric analysis (TG and DTG) of a green varistor tape.

differential thermal analysis (TG, DTG, and DTA curves) are presented for a green varistor laminate. In the temperature range $200-450{ }^{\circ} \mathrm{C}$, a distinct exothermic effect was detected in the DTA curve, accompanied by a rapid mass loss in the TG curve. There occur an inflection point at $308{ }^{\circ} \mathrm{C}$ and two local small maxima at 353 and $420{ }^{\circ} \mathrm{C}$. These exothermic effects are related to burnout of organic components from the green tape.

Changes in dimensions and shape of green varistor samples were observed in a heating microscope (Fig. 2). The sample with the composition given in Table 1 starts to shrink at about $900{ }^{\circ} \mathrm{C}$. A significant shrinkage takes place above $1000{ }^{\circ} \mathrm{C}$. No melting or softening of the sample occurs up to $1350{ }^{\circ} \mathrm{C}$. The temperature range of $1050-1100{ }^{\circ} \mathrm{C}$ was chosen as optimal for effective sintering. The applied firing profile ensures slow burnout of organic components from the green tape and from the electrode paste (in the temperature range of $300-450{ }^{\circ} \mathrm{C}$ ) and subsequent good densification of ceramic layers as a result of high temperature sintering process. The use of $0.5 \mathrm{wt} \%$ of $\mathrm{AlF}_{3}-\mathrm{CaB}_{4} \mathrm{O}_{7}$ sintering aid enabled lowering the sintering temperature from 1050 to $920{ }^{\circ} \mathrm{C}$ due to formation of liquid phase based on this additive. This effect of improved sinterability is illustrated in Fig. 2(b) which shows changes of the sample dimensions for the basic composition with $0.5 \mathrm{wt} \%$ of $\mathrm{AlF}_{3}-\mathrm{CaB}_{4} \mathrm{O}_{7}$ addition. The shrinkage onset was found to decrease from $900{ }^{\circ} \mathrm{C}$ for the basic varistor composition to $830{ }^{\circ} \mathrm{C}$ for the $\mathrm{AlF}_{3}-\mathrm{CaB}_{4} \mathrm{O}_{7}$ enriched composition.

Figures 3(a)-3(c) compare SEM images of ceramic layers in multilayer varistors sintered at different temperatures. The images reveal the characteristic, dense, and fine-grained varistor microstructure composed of relatively big $\mathrm{ZnO}$ grains, thin $\mathrm{Bi}_{2} \mathrm{O}_{3}$-rich films surrounding these grains or segregated at triple grain junctions, and small grains rich in antimony and/or bismuth pinned at grain boundaries. The compatibility of platinum based electrodes with the ceramic layers is very good, as illustrated in Fig. 3(d). The thicknesses of the ceramic layers made of a single varistor green tape are 65,52 , and $45 \mu \mathrm{m}$ for the multilayer samples sintered at 1000,1050 , and $1100{ }^{\circ} \mathrm{C}$, respectively. In general, the microstructure is similar for samples sintered at 1000,1050 , and $1100{ }^{\circ} \mathrm{C}$. However, a moderate growth of $\mathrm{ZnO}$ grains and a decrease in uniformity of $\mathrm{ZnO}$ grain sizes, along with a better densification degree can be observed for the varistors fired at 1050 and $1100{ }^{\circ} \mathrm{C}$. The average grain sizes are $2,2.8$, and $3.3 \mu \mathrm{m}$ for the varistors sintered at 1000,1050 , and $1100{ }^{\circ} \mathrm{C}$, respectively. The varistor composition applied in this study prevents excessive grain growth, thus for well densified samples, which were sintered at 1050 and $1100{ }^{\circ} \mathrm{C}$, the maximal grain sizes do not exceed 5 and $7 \mu \mathrm{m}$, respectively, and a narrow grain size distribution range is maintained. Kuo et al. [28] proved that in a multilayer varistor structure composed of a few $\mathrm{Bi}_{2} \mathrm{O}_{3}$ doped $\mathrm{ZnO}$ layers with different thicknesses ranging from 20 to $140 \mu \mathrm{m}$, the grain growth was constrained by the inert Pt inner electrodes. Both the grain size and the grain size variation decreased with diminishing thickness of the ceramic layer [28]. In this work, no differences were observed between grain sizes in the ceramic layers of 50-250 $\mu \mathrm{m}$ thick, separated by the electrodes in a multilayer structure, and those in

(a)

(b)
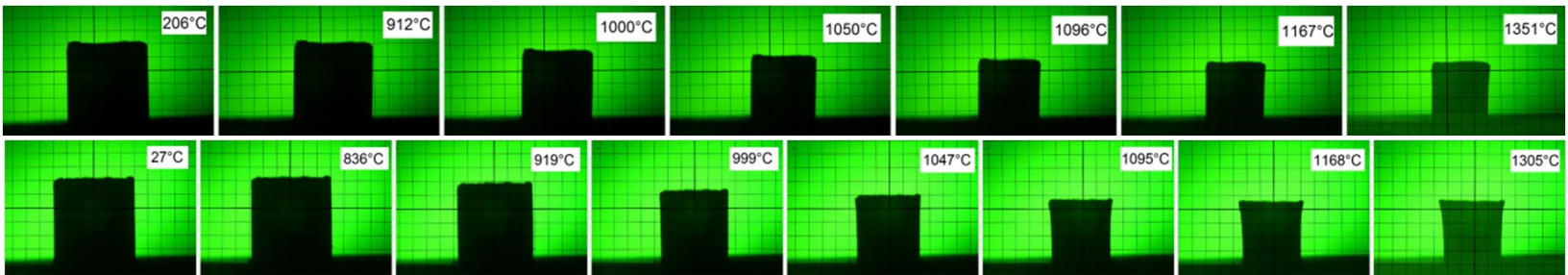

Fig. 2 Heating microscope images of green varistor samples: (a) basic composition, (b) basic composition with $0.5 \mathrm{wt} \%$ of $\mathrm{AlF}_{3}-\mathrm{CaB}_{4} \mathrm{O}_{7}$ sintering aid. 


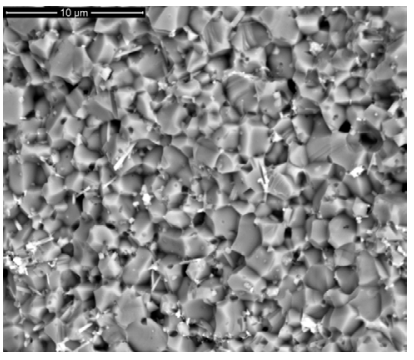

(a)

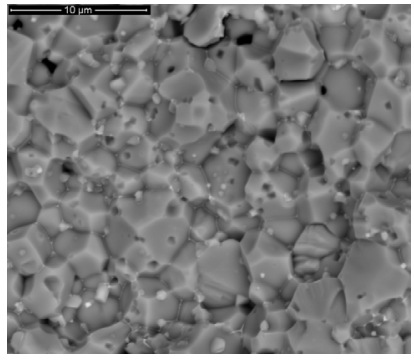

(b)

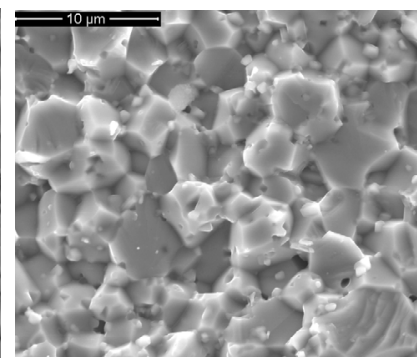

(c)

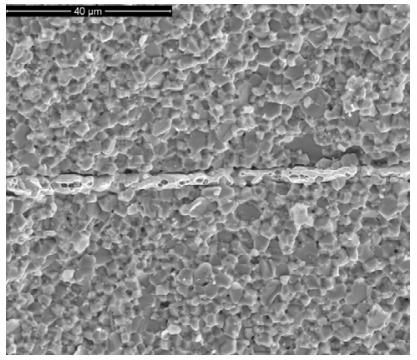

(d)

Fig. 3 SEM images of fractured cross-sections of multilayer varistors sintered at various temperatures: (a) $1000^{\circ} \mathrm{C}, 10000 \times$, (b) $1050{ }^{\circ} \mathrm{C}, 10000 \times$, (c) $1100{ }^{\circ} \mathrm{C}, 10000 \times$, (d) $1100{ }^{\circ} \mathrm{C}, 5000 \times$.

bulk ceramic laminates sintered at the same conditions.

Figures 4(a) and 4(b) display SEM images in the backscattered electron mode for fractured cross-section of a fired multilayer varistor sintered at $1050{ }^{\circ} \mathrm{C}$. The results of EDS analysis in the points 1-5, indicated in Fig. 4(b), are shown in Table 3. Dominant grains of 1-5 $\mu \mathrm{m}$ size (represented by the point 1 in Fig. 4(b) and Table 3), correspond to $\mathrm{ZnO}$. The relatively big $\mathrm{ZnO}$ grains are surrounded by thin nanometric layers rich in bismuth (point 2 in Fig. 4(b) and Table 3) which form at grain boundaries insulating potential barriers responsible for the creation of varistor properties.

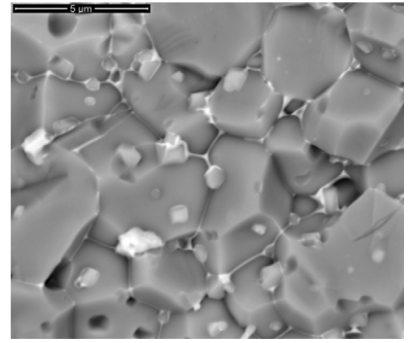

(a)

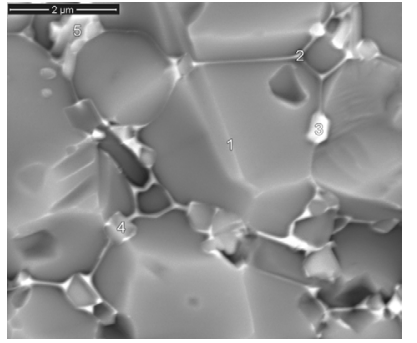

(b)
Fig. 4 SEM images of fractured cross-section of a multilayer varistor sintered at $1050{ }^{\circ} \mathrm{C}$ : (a) $20000 \times$, (b) $40000 \times$. In the points 1-5, EDS analysis was performed.

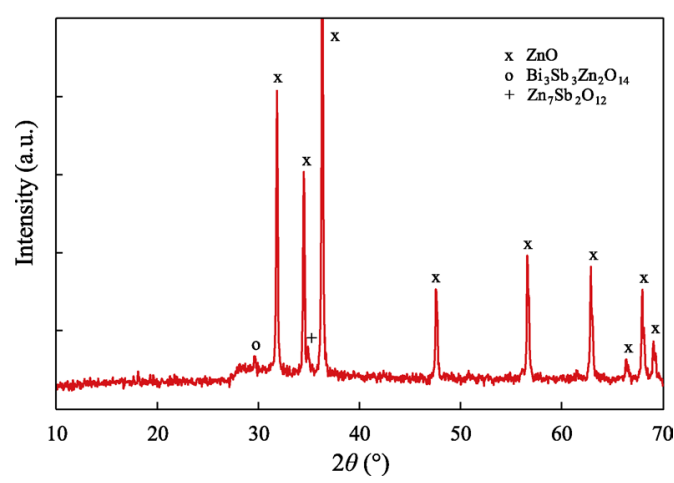

Fig. $5 \mathrm{XRD}$ pattern of the varistor ceramic layer sintered at $1050{ }^{\circ} \mathrm{C}$.
Table 3 Results of EDS analysis in the points marked in Fig. 4(b)

\begin{tabular}{cccccc}
\hline \multirow{2}{*}{ Element } & \multicolumn{5}{c}{ Content (at\%) } \\
\cline { 2 - 6 } & Point 1 & Point 2 & Point 3 & Point 4 & Point 5 \\
\hline $\mathrm{O}$ & 58.13 & 58.07 & 61.41 & 56.26 & 61.18 \\
$\mathrm{Bi}$ & - & 1.85 & - & - & 1.82 \\
$\mathrm{Sb}$ & - & - & 1.20 & 2.57 & 0.55 \\
$\mathrm{Cr}$ & - & - & 1.72 & 2.30 & - \\
$\mathrm{Zn}$ & 41.87 & 40.08 & 35.67 & 38.87 & 36.45 \\
\hline
\end{tabular}

Smaller and brighter grains of $0.3-1 \mu \mathrm{m}$ size, containing elements with higher atomic number are situated at boundaries of $\mathrm{ZnO}$ grains (points 3, 4, and 5 in Fig. 4(b) and Table 3). The EDS spectra determined in these points indicate the presence of zinc, antimony, bismuth, and chromium. These are presumably grains of spinel $\mathrm{Zn}_{7} \mathrm{Sb}_{2} \mathrm{O}_{12}$ or pyrochlore $\mathrm{Bi}_{3} \mathrm{Sb}_{3} \mathrm{Zn}_{2} \mathrm{O}_{14}$ enriched in other dopant elements, such as $\mathrm{Cr}, \mathrm{Co}, \mathrm{Mn}$. The spinel grains are known to play a crucial role in inhibition of growth of $\mathrm{ZnO}$ grains. Spinel phase was reported to undergo reversible transformation into more conductive pyrochlore phase during cooling step [31]. As shown in Fig. 5, the presence of small amounts of spinel and pyrochlore phases was revealed in the XRD pattern besides the prevailing $\mathrm{ZnO}$ phase.

Figure 6 shows SEM images of the fractured cross-section of the multilayer varistor with $0.5 \mathrm{wt} \%$ of $\mathrm{AlF}_{3}-\mathrm{CaB}_{4} \mathrm{O}_{7}$ addition sintered at $920{ }^{\circ} \mathrm{C}$. Owing to lowering of the sintering temperature, the use of cheap silver internal electrodes was possible. As illustrated in Fig. 6(a), the cooperation between Ag conductive layer and varistor ceramic layer is very good. The comparison of Fig. 3(a) and Fig. 6(b) presenting under the same magnification the microstructures for the basic varistor composition sintered at $1000{ }^{\circ} \mathrm{C}$ and for the $\mathrm{AlF}_{3}-\mathrm{CaB}_{4} \mathrm{O}_{7}$ enriched composition sintered at $920{ }^{\circ} \mathrm{C}$ respectively, proves an effective improvement of varistor sinterability 


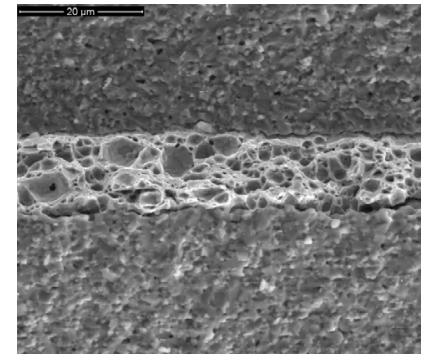

(a)

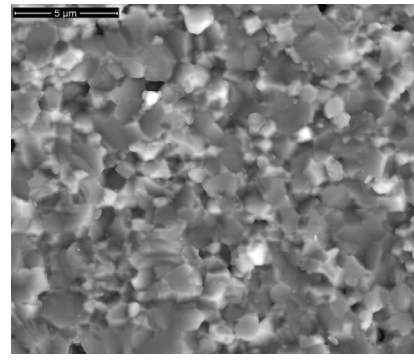

(b)

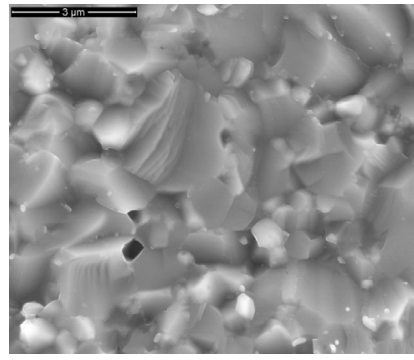

(c)

Fig. $6 \mathrm{SEM}$ images of fractured cross-section of the multilayer varistor with $0.5 \mathrm{wt} \%$ of $\mathrm{AlF}_{3}-\mathrm{CaB}_{4} \mathrm{O}_{7}$ addition, sintered at $920{ }^{\circ} \mathrm{C}$ : (a) $3000 \times$, (b) $10000 \times$, (c) $20000 \times$.

due to the sintering aid presence. The sample with $\mathrm{AlF}_{3}-\mathrm{CaB}_{4} \mathrm{O}_{7}$ is better densified at lower temperature and preserves the characteristic varistor microstructure. Because of lower sintering temperature mean $\mathrm{ZnO}$ grain size for a sample sintered at $920{ }^{\circ} \mathrm{C}$ is slightly lower that that at $1050{ }^{\circ} \mathrm{C}$. Furthermore, from Fig. 6(c) it follows that for the $\mathrm{AlF}_{3}-\mathrm{CaB}_{4} \mathrm{O}_{7}$ enriched varistor thin insulating films at $\mathrm{ZnO}$ grain boundaries responsible for barrier layer effect could not be so easily recognized as for the same composition without the applied sintering aid (Fig. 4(b)).

The leakage current of the fabricated varistors with the basic composition decreases with increasing sintering temperature. The values of this parameter determined at $80 \% U_{1 \mathrm{~mA}}$ are 124,117 , and $81 \mu \mathrm{A} / \mathrm{cm}^{2}$ for the varistors sintered at 1000,1050 , and $1100{ }^{\circ} \mathrm{C}$, respectively.

In Figs. 7(a) and 7(b) the current-voltage characteristics are depicted for the varistors sintered at 1000, 1050, and $1100{ }^{\circ} \mathrm{C}$. Above the breakdown voltage $V_{\mathrm{b}}$, a rapid increase in current and transition to the region of nonlinear characteristic of the varistor occurs which results from an abrupt decrease in the varistor resistance. There is a strong dependence of the breakdown voltage on the sintering temperature. The breakdown voltages were found to be 130,80 , and $66 \mathrm{~V}$ for varistors sintered at 1000,1050 , and $1100{ }^{\circ} \mathrm{C}$, respectively. The observed decrease in breakdown voltage with the rising sintering temperature is consistent with the results of several authors $[11,16,18,23,25]$. Lower values of the breakdown voltage for the varistors sintered at higher temperatures are due to the grain growth and consequently a decrease in the grain boundary number between the adjacent electrodes. The electrostatic barrier created at Bi-rich boundaries of $\mathrm{ZnO}$ grains was estimated to be at a level of about $3 \mathrm{~V}[2,27]$. The breakdown voltage of a multilayer varistor increases linearly with increasing

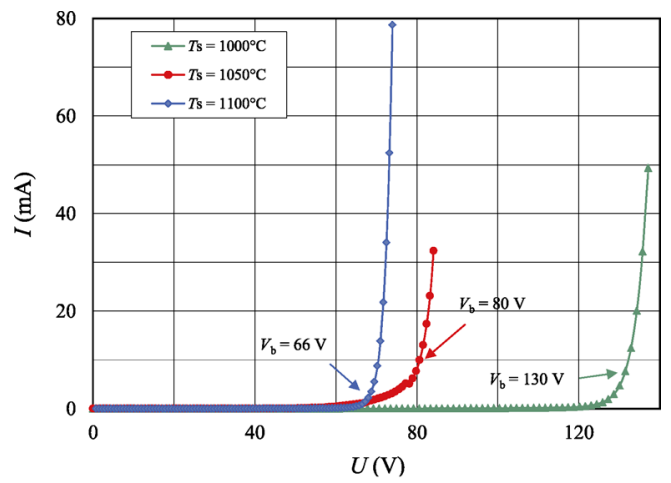

(a)

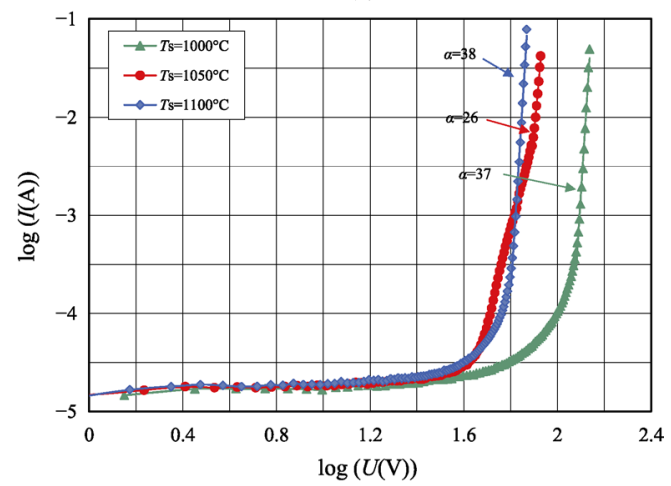

(b)

Fig. 7 Current-voltage characteristics of multilayer varistors sintered at various temperatures: (a) $I-U$, (b) $\log I-\log U$.

number of grain boundaries between inner electrodes [27]. Generally, application of ceramic layers with an enhanced thickness leads to an increase of the number of grain boundaries and consequently to a higher breakdown voltage. However, this effect can be to some extent suppressed by facilitated grain growth due to a larger space between internal electrodes [27]. In this work, it was stated that both the breakdown voltage and the nonlinear coefficient are higher when the thickness of the varistor layers is increased. Since for multilayer varistors the breakdown voltage is proportional 
to the total number of active grain boundaries between the inner electrodes, this crucial varistor parameter can be easily tailored by changing the thickness of the varistor layer as well as to some extent by changing the sintering temperature.

The nonlinear coefficients $\alpha$ determined from the slope of the $\log I=f(\log U)$ plots presented in Fig. 7(b) are 38,26 , and 37 for the sintering temperatures of 1000,1050 , and $1100{ }^{\circ} \mathrm{C}$, respectively. The effect of the sintering temperature on this parameter is not clear. The results obtained by other authors are also ambiguous and strongly dependent on the specific varistor composition and the considered sintering temperature range. In general, it seems that nonlinear coefficient grows with sintering temperature up to attaining optimal sintering range corresponding to the proper microstructure and then drops with further increasing of this temperature. Numerous and often contradictory temperature dependent factors are supposed to have impact on the dependence of nonlinear coefficient on sintering temperature, such as bismuth loss due to volatilization, uniform distribution of additives, solubility of additives in bismuth-rich phase, secondary phase formation at grain boundaries, oxygen content, changes in the grain boundary resistivity, fraction of electrically active grain boundaries. For rare-earth doped $\mathrm{ZnO}$ varistors, lowering of nonlinear coefficient with increasing sintering temperature was observed and assigned to changes in grain boundary resistivity [11]. A decrease in nonlinear coefficient with sintering temperature, attributed to the diminished grain boundary number, was also reported for the multilayer varistor based on $\mathrm{ZnO}$ doped with $\mathrm{Al}, \mathrm{Mn}$, $\mathrm{Co}, \mathrm{Sb}$, and Bi oxides [25]. For ceramic varistors based on pure $\mathrm{ZnO}$, nonlinear coefficient grew with sintering temperature changing in the range $800-1100{ }^{\circ} \mathrm{C}$, remained constant for 1100 and $1200{ }^{\circ} \mathrm{C}$, and significantly decreased when the sintering temperature was raised to a high temperature of $1400{ }^{\circ} \mathrm{C}$ [18].

Figures 8(a) and 8(b) present the complex impedance plots for a multilayer varistor at a few selected temperatures in the range from -30 to $150{ }^{\circ} \mathrm{C}$. The dominant response represented in the Nyquist plot by a big arc is related to grain boundaries. The resistances of grain boundaries are high, decreasing from $10^{8} \Omega$ at $-30{ }^{\circ} \mathrm{C}$ to $10^{5} \Omega$ at $150{ }^{\circ} \mathrm{C}$. The frequencies corresponding to the maximum of $Z^{\prime \prime}=f\left(Z^{\prime}\right)$ arcs are below $1 \mathrm{~Hz}$ at temperatures up to $150{ }^{\circ} \mathrm{C}$. Such low frequencies indicate that space charge polarization is responsible for dielectric relaxation in this region. The response of

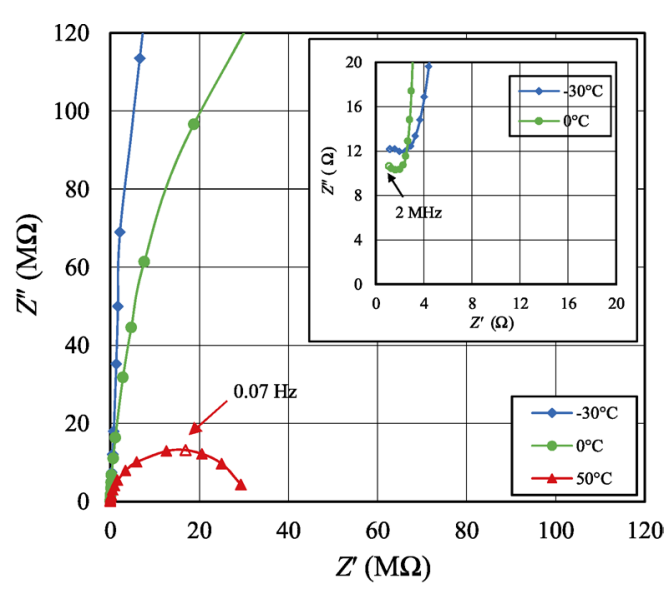

(a)

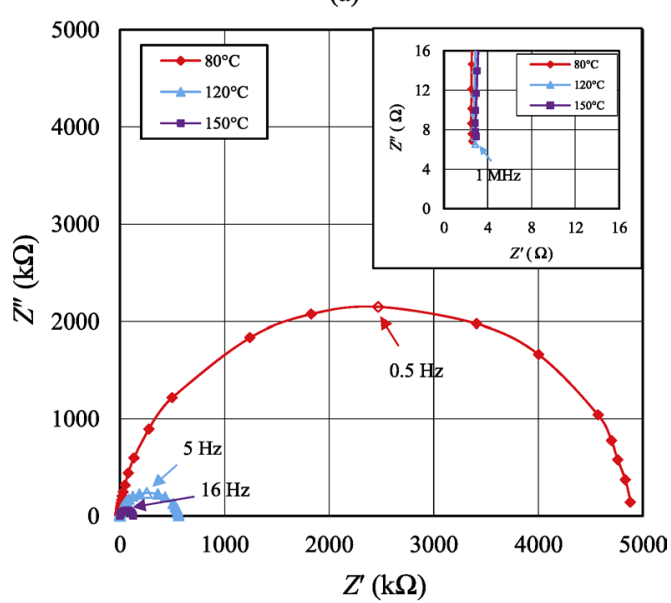

(b)

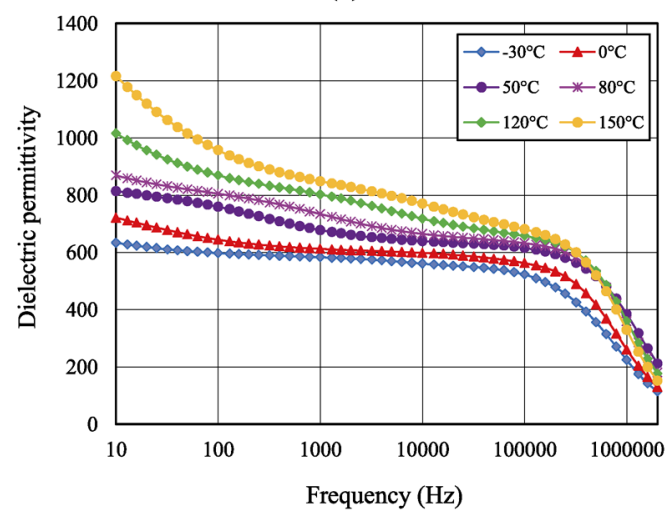

(c)

Fig. 8 (a, b) Complex impedance plots, (c) dielectric permittivity versus frequency at a few selected temperatures in the range from -30 to $150{ }^{\circ} \mathrm{C}$, for a multilayer varistor sintered at $1050{ }^{\circ} \mathrm{C}$.

grains can be detected only at low temperatures and high frequencies. In the inset of Fig. 8(a), a small depressed arc attributed to this response is visible at -30 and $0{ }^{\circ} \mathrm{C}$. At higher temperatures, the nonzero intercept with the real axis implies the existence of a 
high frequency arc beyond the measurement range, as illustrated in the inset of Fig. 8(b). The resistance of grains assessed at a level of $\Omega$ is low and slightly temperature dependent. The ratio of the resistivities of grain boundaries and grains is high. This leads to creation of potential barriers at grain boundaries responsible for the varistor behavior.

In Fig. 8(c), the dielectric permittivity of the varistor ceramic is plotted as a function of frequency in the range $10-2 \times 10^{6} \mathrm{~Hz}$ for a few temperatures ranging from -30 to $150{ }^{\circ} \mathrm{C}$. High $(600-1200)$ and slightly frequency dependent values of dielectric permittivity at low frequency region followed by an abrupt drop at higher frequencies above $\left(10^{5} \mathrm{~Hz}\right)$ are characteristic for the barrier layer capacitance effect. Dielectric permittivity for grain boundary barrier layer capacitors, to which $\mathrm{ZnO}$ varistors belong, is proportional to dielectric permittivity of the insulating barrier at grain boundaries and the grain size, and inversely proportional to the thickness of this barrier layer $\left(\varepsilon \approx \varepsilon_{\mathrm{gb}} d_{\mathrm{g}} / d_{\mathrm{gb}}\right.$, where $\varepsilon_{\mathrm{gb}}$ is the dielectric permittivity of the grain boundary layer, $d_{\mathrm{g}}$ is the grain size, and $d_{\mathrm{gb}}$ is the thickness of the grain boundary). Raising of the sintering temperature does not change markedly dielectric permittivity of the insulating barrier layer, but results in grain growth and an increase in the insulating layer thickness, which can lead to a decrease of the dielectric permittivity [11].

Figure 9 presents the current-voltage characteristics for the multilayer varistor with $0.5 \mathrm{wt} \%$ of $\mathrm{AlF}_{3}-\mathrm{CaB}_{4} \mathrm{O}_{7}$. Although SEM observations (Fig. 6) indicated that the microstructure of a varistor ceramic doped additionally with $0.5 \mathrm{wt} \% \mathrm{AlF}_{3}-\mathrm{CaB}_{4} \mathrm{O}_{7}$ as a sintering aid remains dense and similar to that for the basic material without this additive, the varistor properties were found to be worse. The breakdown voltage of the multilayer varistor with the single ceramic layer thickness of 170 $\mu \mathrm{m}$ remains at a high level of $280 \mathrm{~V}$ (Fig. 9(a)), but the nonlinear coefficient decreases to a lower value of 9 (Fig. 9(b)). At sintering temperature of $920{ }^{\circ} \mathrm{C}$, $\mathrm{AlF}_{3}-\mathrm{CaB}_{4} \mathrm{O}_{7}$ addition forms a liquid phase and enters the grain boundary region. This effect facilitates sintering process, does not decrease breakdown voltage, although it diminishes the nonlinear coefficient. This implies that proper functioning of the blocking layers at the grain boundaries was degraded probably due to a disadvantageous change in the composition of these regions. Elucidation of this effect needs further studies.

Figure 10(b) shows the current-voltage characteristics for the basic varistor composition before and after

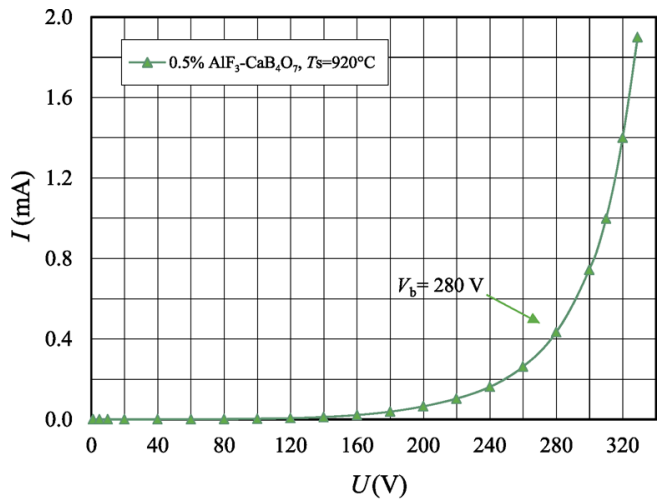

(a)

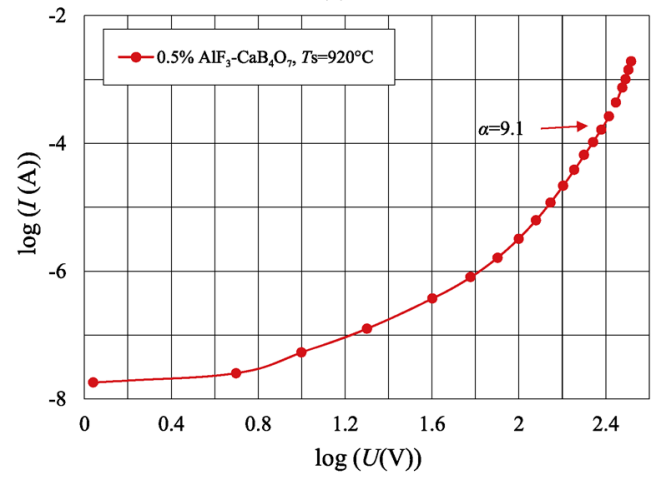

(b)

Fig. 9 Current-voltage characteristics of the multilayer varistor with $0.5 \mathrm{wt} \%$ of $\mathrm{AlF}_{3}-\mathrm{CaB}_{4} \mathrm{O}_{7}$, sintered at $920{ }^{\circ} \mathrm{C}$ : (a) $I-U$, (b) $\log I-\log U$.

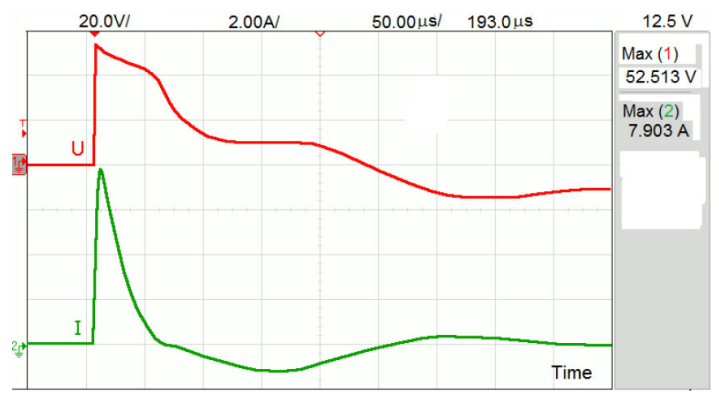

(a)

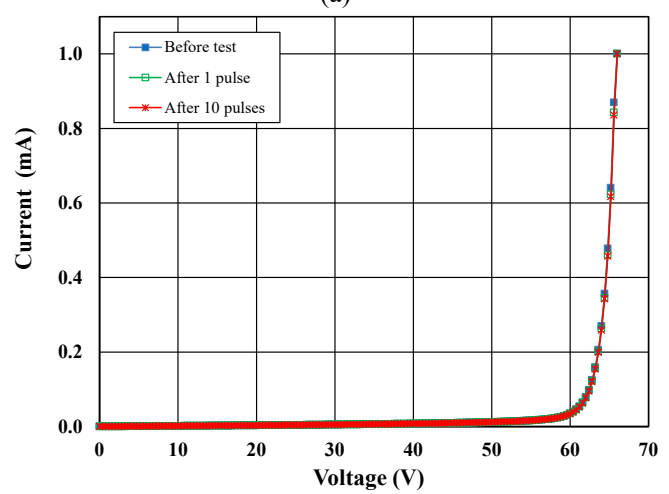

(b)

Fig. 10 (a) Impulse shape used for the surge current test $(8 / 20 \mu \mathrm{s})$, (b) $I-U$ characteristics of a multilayer varistor sintered at $1100{ }^{\circ} \mathrm{C}$ before and after the surge test. 
surge testing using the pulse shape $8 / 20 \mu$ s for short-circuit current presented in Fig. 10(a). The ability of the multilayer varistor to withstand these pulses is very good. The changes in the course of the $I=f(U)$ characteristics after applying of 10 pulses are small, at a level of about $1 \%$.

\section{Conclusions}

The composition of green varistor tapes based on $\mathrm{ZnO}$ doped with $\mathrm{Bi}, \mathrm{Sb}, \mathrm{Co}, \mathrm{Mn}, \mathrm{Cr}, \mathrm{B}$, and $\mathrm{Si}$ oxides as well as processing procedure of multilayer varistors were optimized basing on heating microscope and DTA studies. A proper, uniform, and fine-grained varistor microstructure was attained that resulted in the formation of effective potential barriers at $\mathrm{ZnO}$ grain boundaries. The size of $\mathrm{ZnO}$ grains was not dependent on the thickness of the ceramic layers ranging from 50 to $250 \mu \mathrm{m}$. The developed multilayer varistors exhibited good nonlinear electric properties. The dominant dielectric response represented by a big arc in the complex impedance plots was related to grain boundaries. The breakdown voltages of the varistors were 66-130 V and decreased with increasing sintering temperature due to a moderate grain growth. The nonlinear coefficients were relatively high, at a level of 26-38. After surge current tests the current-voltage characteristics were found to remain almost unchanged.

Effective lowering of the sintering temperature to a level of $920{ }^{\circ} \mathrm{C}$ enabling the use of cheap $\mathrm{Ag}$ internal electrodes due to a small addition of $\mathrm{AlF}_{3}-\mathrm{CaB}_{4} \mathrm{O}_{7}$ was accompanied by inferior nonlinear varistor behavior as compared with the composition without this additive. This experiment proved that the varistor composition is a delicate balance and the desired properties of grain boundary barriers can be easily degraded.

\section{Acknowledgements}

The work has been supported by the National Science Centre, Poland, under the Grant No. 2015/17/D/ST7/04141.

\section{References}

[1] Gupta TK. Application of zinc oxide varistors. J Am Ceram Soc 1990, 73: 1817-1840.

[2] Clarke DR. Varistor ceramics. J Am Ceram Soc 2004, 82: 485-502.
[3] Bueno PR, Varela JA, Longo E. $\mathrm{SnO}_{2}, \mathrm{ZnO}$ and related polycrystalline compound semiconductors: An overview and review on the voltage-dependent resistance (non-ohmic) feature. J Eur Ceram Soc 2008, 28: 505-529.

[4] Pillai SC, Kelly JM, Ramesh R, et al. Advances in the synthesis of $\mathrm{ZnO}$ nanomaterials for varistor devices. $J$ Mater Chem C 2013, 1: 3268-3281.

[5] Zhao HF, Hu J, Chen SM, et al. Tailoring the high-impulse current discharge capability of $\mathrm{ZnO}$ varistor ceramics by doping with $\mathrm{Ga}_{2} \mathrm{O}_{3}$. Ceram Int 2016, 42: 5582-5586.

[6] Wang YP, Zhang GZ, Liu P, et al. The clamp characteristics and $\mathrm{DC}$ aging behavior of $\mathrm{ZnO}$-based varistor ceramics doped with $\mathrm{Na}_{2} \mathrm{CO}_{3}$. Ceram Int 2016, 42: 2106-2114.

[7] Pandey S, Kumar D, Parkash O. Investigation of the electrical properties of liquid-phase sintered $\mathrm{ZnO}-\mathrm{V}_{2} \mathrm{O}_{5}$ based varistor ceramics using impedance and dielectric spectroscopy. J Mater Sci: Mater Electron 2016, 27: 3748-3758.

[8] Nahm CW. Effect of dopant (Al, Nb, Bi, La) on varistor properties of $\mathrm{ZnO}-\mathrm{V}_{2} \mathrm{O}_{5}-\mathrm{MnO}_{2}-\mathrm{Co}_{3} \mathrm{O}_{4}-\mathrm{Dy}_{2} \mathrm{O}_{3}$ ceramics. Ceram Int 2010, 36: 1109-1115.

[9] Bai HR, Zhang $\mathrm{MH}, \mathrm{Xu} \mathrm{ZJ}$, et al. The effect of $\mathrm{SiO}_{2}$ on electrical properties of low-temperature-sintered $\mathrm{ZnO}-\mathrm{Bi}_{2} \mathrm{O}_{3}-\mathrm{TiO}_{2}-\mathrm{Co}_{2} \mathrm{O}_{3}-\mathrm{MnO}_{2}$-based ceramics. $\mathrm{J} \mathrm{Am}$ Ceram Soc 2017, 100: 1057-1064.

[10] Ezhilvalavan S, Kutty TRN. Dependence of non-linearity coefficients on transition metal oxide concentration in simplified compositions of $\mathrm{ZnO}+\mathrm{Bi}_{2} \mathrm{O}_{3}+\mathrm{MO}$ varistor ceramics ( $\mathrm{M}=\mathrm{Co}$ or $\mathrm{Mn})$. J Mater Sci: Mater Electron 1996, 7: 137-148.

[11] Cai JN, Lin YH, Li M, et al. Sintering temperature dependence of grain boundary resistivity in a rare-earth-doped $\mathrm{ZnO}$ varistor. $J$ Am Ceram Soc 2007, 90: 291-294.

[12] Peiteado M, Reyes Y, Cruz AM, et al. Microstructure engineering to drastically reduce the leakage currents of high voltage $\mathrm{ZnO}$ varistor ceramics. J Am Ceram Soc 2012, 95: 3043-3049.

[13] Ma S, Xu ZJ, Chu RQ, et al. Low-temperature sintering and electrical properties of Co-doped $\mathrm{ZnO}$ varistors. $J$ Mater Sci: Mater Electron 2014, 25: 3878-3884.

[14] Zhu JF, Qi GQ, Yang HB, et al. Microstructure and electrical properties of $\mathrm{Pr}_{6} \mathrm{O}_{11}$ doped $\mathrm{ZnO}-\mathrm{Bi}_{2} \mathrm{O}_{3}$-based varistors. J Mater Sci: Mater Electron 2011, 22: 96-100.

[15] Wu J, Qi T, Li TT, et al. The AC impedance and variable temperature dielectric spectroscopic analysis of $\mathrm{MnO}_{2}$ doped and un-doped $\mathrm{ZnO}-\mathrm{V}_{2} \mathrm{O}_{5}$ ceramics. J Mater Sci: Mater Electron 2012, 23: 1143-1150.

[16] Xiao XK, Zheng LY, Cheng LH, et al. Effect of $\mathrm{Cr}_{2} \mathrm{O}_{3}$ on the property and microstructure of $\mathrm{ZnO}-\mathrm{Bi}_{2} \mathrm{O}_{3}$ varistor ceramics in different sintering temperature. Ceram Int 2015, 41: S557-S562.

[17] Tsonos C, Kanapitsas A, Triantis D, et al. Interface states and MWS polarization contributions to the dielectric response of low voltage $\mathrm{ZnO}$ varistor. Ceram Int 2011, 37: 
207-214.

[18] Sedky A, El-Brolossy TA, Mohamed SB. Correlation between sintering temperature and properties of $\mathrm{ZnO}$ ceramic varistors. J Phys Chem Solids 2012, 73: 505-510.

[19] Bueno PR, Leite ER, Oliveira MM, et al. Role of oxygen at the grain boundary of metal oxide varistors: A potential barrier formation mechanism. Appl Phys Lett 2001, 79: $48-50$.

[20] Ramírez MA, Simões AZ, Márquez MA, et al. Characterization of $\mathrm{ZnO}$-degraded varistors used in high-tension devices. Mater Res Bull 2007, 42: 1159-1168.

[21] Chen T, Zu H, Gao C, et al. Preparation and electrical properties of $\mathrm{ZnO}-\mathrm{Bi}_{2} \mathrm{O}_{3}$-based multilayer varistors with base metal nickel inner electrodes. J Am Ceram Soc 2017, 100: 3024-3032.

[22] Hirose S, Nishita K, Niimi H. Influence of distribution of additives on electrical potential barrier at grain boundaries in ZnO-based multilayered chip varistor. J Appl Phys 2006, 100: 083706.

[23] Lee WS, Chen WT, Lee YC, et al. Influence of sintering on microstructure and electrical properties of ZnO-based multilayer varistor (MLV). Ceram Int 2007, 33: 1001-1005.

[24] Hirose S, Niimi H, Kageyama K, et al. Degradation of potential barriers in $\mathrm{ZnO}$-based chip varistors due to electrostatic discharge. J Appl Phys 2012, 112: 033707.

[25] Lee WH, Chen WT, Lee YC, et al. Relationship between microstructure and electrical properties of ZnO-based multilayer varistor. Jpn J Appl Phys 2006, 45: 5126-5131.

[26] Wan S, Lu WZ, Wang XC. Low-temperature sintering and electrical properties of $\mathrm{ZnO}-\mathrm{Bi}_{2} \mathrm{O}_{3}-\mathrm{TiO}_{2}-\mathrm{Co}_{2} \mathrm{O}_{3}-\mathrm{MnCO}_{3}$ based varistor with $\mathrm{Bi}_{2} \mathrm{O}_{3}-\mathrm{B}_{2} \mathrm{O}_{3}$ frit for multilayer chip varistor applications. $J \mathrm{Am}$ Ceram Soc 2010, 93: 3319-3323.

[27] Pan WH, Kuo ST, Tuan WH, et al. Microstructure-property relationships for low-voltage varistors. Int J Appl Ceram Technol 2009, 7: E80-E88.

[28] Kuo ST, Tuan WH, Lao YW, et al. Grain growth behavior of $\mathrm{Bi}_{2} \mathrm{O}_{3}$-doped $\mathrm{ZnO}$ grains in a multilayer varistor. $\mathrm{J} \mathrm{Am}$ Ceram Soc 2008, 91: 1572-1579.

[29] Kuo ST, Tuan WH, Lao YW, et al. Inner electrodes for multilayer varistors. Int J Appl Ceram Technol 2009, 6: 223-230.

[30] Kuo ST, Tuan WH. Grain growth behaviour of $\mathrm{ZnO}$-based multilayer varistors. J Eur Ceram Soc 2010, 30: 525-530.

[31] Peiteado M, de la Rubia MA, de Frutos J, et al. ZnO-based varistor thick films with high non-linear electrical behavior. J Electroceram 2009, 23: 62-66.
[32] Wang LY, Tang GY, Xu ZK. Preparation and electrical properties of multilayer $\mathrm{ZnO}$ varistors with water-based tape casting. Ceram Int 2009, 35: 487-492.

[33] Kulawik J, Szwagierczak D, Synkiewicz B. Tape casting and properties of $\mathrm{Pr}_{2} \mathrm{O}_{3}$-doped $\mathrm{ZnO}$ multilayer varistors. Microelectron Int 2014, 31: 163-168.

[34] Kulawik J, Szwagierczak D, Skwarek A. Electrical and microstructural characterization of doped $\mathrm{ZnO}$ based multilayer varistors. Microelectron Int 2017, 34: 116-120.

[35] Manoharan G, Karuppiah M, Sahu NK, et al. High performance multi-layer varistor (MLV) from doped $\mathrm{ZnO}$ nanopowders by water based tape casting: Rheology, sintering, microstructure and properties. Ceram Int 2018, 44: 7837-7843.

[36] Tan DQ, Chapman Irvin P, Younsi A. Electronic device and method. US Patent 82117751. 2012.

[37] Okamoto N, Ito H, Kida T. Sintered body for varistor, multilayer substrate using same, and production method for these. US Patent 9741477 B2. 2017.

[38] Lien CH, Zhu JA, Xu ZX, et al. Multilayer varistor and process for producing the same. US Patent 9947444B1. 2018.

[39] Dernovsek O, Koholka J. Method for producing a multi-layer varistor component and multi-layer varistor component. US Patent, 9875831 B. 2018.

[40] Xu ZJ, Bai HR, Ma S, et al. Effect of a Bi-Cr-O synthetic multi-phase on the microstructure and electrical properties of $\mathrm{ZnO}-\mathrm{Bi}_{2} \mathrm{O}_{3}$ varistor ceramics. Ceram Int 2016, 42: 14350-14354.

[41] Hofstätter M, Nevosad A, Teichert C, et al. Voltage polarity dependent current paths through polycrystalline $\mathrm{ZnO}$ varistors. J Eur Ceram Soc 2013, 33: 3473-3476.

Open Access This article is licensed under a Creative Commons Attribution 4.0 International License, which permits use, sharing, adaptation, distribution and reproduction in any medium or format, as long as you give appropriate credit to the original author(s) and the source, provide a link to the Creative Commons licence, and indicate if changes were made.

The images or other third party material in this article are included in the article's Creative Commons licence, unless indicated otherwise in a credit line to the material. If material is not included in the article's Creative Commons licence and your intended use is not permitted by statutory regulation or exceeds the permitted use, you will need to obtain permission directly from the copyright holder.

To view a copy of this licence, visit http://creativecommons.org/licenses $/$ by $/ 4.0 /$. 